IN MEMORIAM

\title{
PROF. ULYSSES PERNAMBUCANO
}

HOMENAGEM DE

ARQUIVOS DE NEURO-PSIQUIATRIA 


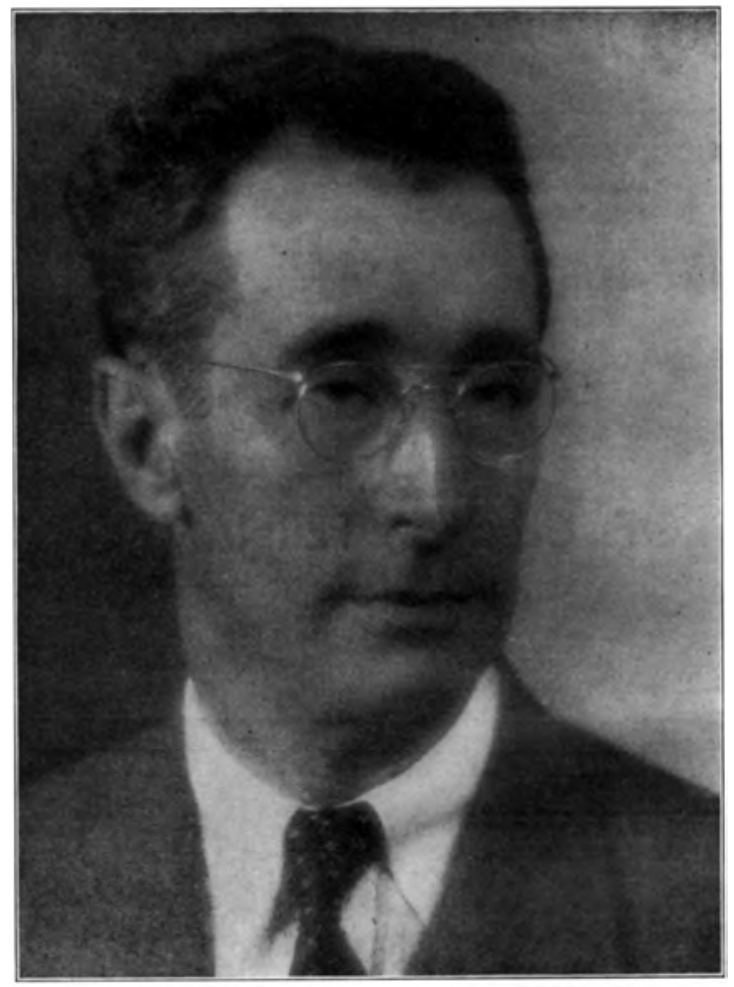

PROFESSOR ULYSSES PERNAMBUCANO 
A neuro-psiquiatria brasileira sofreu rude golpe com a morte do Prof. Ulysses Pernambucano, ocorrida em 5 de Dezembro de 1943, no Rio dé Janeiro. Discípulo de Juliano Moreira e estudioso infatigavel, o pranteado catedrático de Clínica Neurológica na Faculdade de Médicina do Recife, criou em Pernambuco notavel escola neuro-psiquiátrica, traçando rovos rumos e orientando novos valores. Cultor emérito da psicologia. corporificou os fundamentos de uma obra magnifica que ficará perene na memória de seus discípulos a à qual serão gratos todos os brasileiros.

Foi interno do Hospital de Alienados, tendo-se diplomado em 1912, pela Faculdade de Medicina do Rio de Janeiro. Voltando a Pernambuco, foi nomeado adjunto, substituto e alienista do Hospital de Tamarineira de 1916 a 1938. Iniciou sua atividade didática regendo a cadeira de Psicologia da Escola Normal de Pernambuco, após brithante concurso, chegando, em 1925, a diretor dessa casa de estudos. Nesse cargo reformou os antigos métodos de ensino e introduziu o critério da idade mental como condição de admissão, em substituição aos atestados de idade cronológica. Interessou as alunas nos problemas de Psicologia, especialmente da psicometria e fundou o Instituto de Psicologia de Pernambuco. Deixou o cargo de diretor da Escola Normal para reger a cadeira de Neuro-Psiquiatria Infantil na Facu'dade de Medicina do Recife, e' depois, pelo falecimento de Gouveia de Barros, ocupou a cadeira de Clínica Neurológica.

Em 1931 foi convidado para organizar a Assistência a Psicopatas de Pernambuco. Transformou o Azilo da Tamarineira em hospital fechado, dotando-o com um sanatório para pensionistas; dotou a secção Faustino Esposel com dois pavilhões destinados a pacientes crônicas, enquanto não era construida, em Barreinas, uma colônia para mulheres; criou um serviço aberto composto de ambulatório neuro-psiquiátrico e pequena organização hospitalar para internamento de cásos que necessitassem de tratamento imediato e por curto periodo; criou a Colonia de Allienados de Barreiros afim de tratar pelo método de Simon os alienados crônicos, anexando-lhe uma organização de co'ocação familiari criou um Serviço de Higiene Mental para a prevenção das psicopatias e para a prática de serviço social psiquiátrico; anéxou à Assistência a Psicopałas o Instituto de Psicologia; criou, anexo ao Hospital de Alienados, o Manicômio Judiciário; fundou os Arquivos da Assistência a Psicopatas de Pernambuco, repositório dos trabalhos científicos por êle inspirados.

Grande propugnador da coopenação científica, muito trabalhou nesse campo, criando a Liga de Higiene Mental de Pernambuco e a Sociedade de Neurologia, Psiquiatria e Higiene Mental do Nordeste Brasileiro. Ena membro correspondente da Sociedade Brasileira de Neurologia, Psiquiatria e Medicina Legal (Rio de Janeiro), sócio efetivo e ex-presidente da So- 
ciedade de Medicina de Pernambuco. Sócio efetivo e ex-presidente do Sindicato dos Medicos de Pernambuco. Fundador e atual presidente da Sociedade de Neuróogia, Psiquiatria e Higiene Mental do Brasil. Membro correspondente da Academia Nacional de Medicina. Membro honorário da Sociedade de Psiquiatria e Medicina Legal de La Plata (Argentina). Participou do 2. ${ }^{\circ}$ Congresso Latino-Americano de Neurologia, Psiquiatria e Medicina Legal (1932) e dos tres Congressos da Sociedade de Neurologia, Psiquiatria e Higiene Mental do Nordeste, (João Pessoa 1938, Aracajú 1940, Natal 1943). Fundou e dirigiu "Neurob.ologia".

A raiz do dinamismo da obra de Ulysses Pernambuco está na sua formação e na orientação que sempre seguiu. Tinha perfeito conhecimento das diversas doutrinas filosóficas e' pendor para a psicologia individual e coletiva, ao lado de brilhantes qualidades de administrador. Pouco antes de falecer interessara-se pelas relações da sociologia com a psiquiatria. Sua última iniciativa, infelizmente não concluida, foi a da seleção, em Pernambuco, dos elementos componentes do Corpo Expedicionário Brasileiro, mediante uma triagem psicométrica e reclassificação dos soldados nas armas e serviços, mediante provas de seleção profissiona!.

Dentre suas pubicações, de tacam-se: Sobre algumas manifestações nervosas da. heredo-sífilis. Tése de doutoramento, Rio de Janeiro 1912; Educação das crianças anormais de inteligência. Recife, 1918; Bases fisico-psicológicas da ambidextria. Recife, 1919; Estudo psicoténico de alguns testes de aptidão (colab. com Anita Pais Barretol. Jornal de Med. Pernambuco, 1927; Ensáio de aplicação das 100 questões. cie Bellard (colab. com Anita Pais Barreto). Arq. Brasie eiros de Higiene Mental, 1930; O vocabuiário das crianças das escolas primárias do Recife (colab. com Anito Pais Barreto). Arq. da Assistencia a Psicopatas de Pernambuco, 1931; Quocientes de inteligencia em escolares do Recife (colab. com Maria Leopoldina de Oiiveira). Arq. Assist. Psicop. Pernambuco, 1932; O teste, a bola e o campo em crianças de 12 a 13 anos (co ab. com Alda Campcs). Arq. Assist. Psicop. Pernambuco, 1931; Assistência a Psicopatas em Pernambuco. Idéas e realizações. Arq. Assist. Psicop. Pernambuco. 1932: As doenças mentais entre os negros de Pernambuco (colab, com He ena Campos). Arq. Assist. Psicop. Pernambuco, 1932; Um caso de palilalia post-encefalítica /colab com José Lucena). Arq. Assist. Psicop. Pernambuco, 1932 Estudo estatístico da paralisia geral. Arq. As:ist. Psicop. de Pernambuco, 1933; O trabalho dos alienados. na Assistência a Psicopatas de Pernambuco. Arq. Assist. Psicop. Pernambuco, 1934; As doenças mentais entre os negros de Pernambuco. Estudo Afro-Brasileiro. Editora Ariel, R:o de Janẹiro, 1935; Algurs dados antropológicos, da população do Recife (colab. com A. Di Lascio, J. Pernambucano e A. Guimarães). Arq. Assist. Psicop. Pernambuco, 1935; Organização de um curso de extensão universitária sobre Higiene Mental na Fac. de M'edicina do Recfie. Arq. Assist. Psicop. Pernambuco, 1935; Recursos modernos de assistência oos doentes mentais. Neurobiologia, I, 1938; Seis casos de miotonia congênita. Neurobiologia, 2, 1939; Um caso de atrofia muscular pseudo. hipertrófica (colab. com Jarbas Pernambucano). Neurobiologia, 2, 1939; A neuro. mielite epidêmica (doença de Austregésilo) em Pernambuco (colab. com A. Di Lascio a A. Benicio). Neurobiologia, 3, 1940; Síndrome da atrofia paleo-cerebelar (co'ab. com A. Couceiro). Neurobiologia, 3, 1940; Estudo estatístico das doenças mentais encontradas em quatrocentos primeiros internados em casa de saúde particular (colab. com A. Di Lascio). Neurobiologia, 3, 1940; Neuro-psiquiatria forense. (laudos) Neurobiologia, 4, 1941; Ação social do pșiquiatra. Neurobiologia, 6, 1943. 